\title{
MODELO DE OCORRÊNCIA E GÊNESE DA ARGILA BENTONITICA DE BOA VISTA, CAMPINA GRANDE, PARAIIBA
}

\author{
TUMKUR RAJARAO GOPINATH*, HANS-DIETER SCHUSTER* e WALTER KLAUS SCHUCKMANN**
}

\begin{abstract}
Bentonitic clay deposits of Boa Vista region, Paraíba, occur in small basins distributed over a distance of $10 \mathrm{~km}$, and are surrounded by Tertiary basalts and Precambrian granites and gneisses. These argilaceous sediments are caracterized by horizontal laminations, intercalations of sand and silt, and rhythmic interlaminations of clay and silica toward top of the sequence. There is a close genetic relationship between the bentonitic clay and the basaltic flows. Clay sequences in the eastern part of the region are not only underlain by altered, green, vesicular and scoriaceous flows, but also enclosed by similar but unaltered flows. Lapilli tuff pyroclastics occur sporadically over the flows surrounding the clay basin. The basaltic flows and lapillis are rich in volcanic glass and vitric basalt fragments. These basaltic flows contain columnar joints, flow structures and vitrified zones. Volcanic glass in the flows below the clay sequence is devitrified to clay particles and quartz with "ghost" structure, whereas the plagioclase laths are partially replaced by calcedony. In the western part of the region, the bentonitic clay overly gneissic rocks and the basaltic flows in and around these clay deposits are lacking. It is concluded that the bentonitic clays of Boa Vista are the product of devitrification and alteration of glassy pyroclastics that were deposited in the existing basins. These pyroclastics were originated as a result of explosive volcanic activity locally confined to the eastern part of the region.
\end{abstract}

INTRODUÇÃo Os depósitos de bentonita de Boa Vista, Campina Grande, Paraiba, conformam pequenas bacias espalhadas irregularmente na direção leste-oeste da região. As jazidas estão distribuídas, geograficamente, entre as localidades de Juá, Lages e Bravo (Figs. 1 e 2).

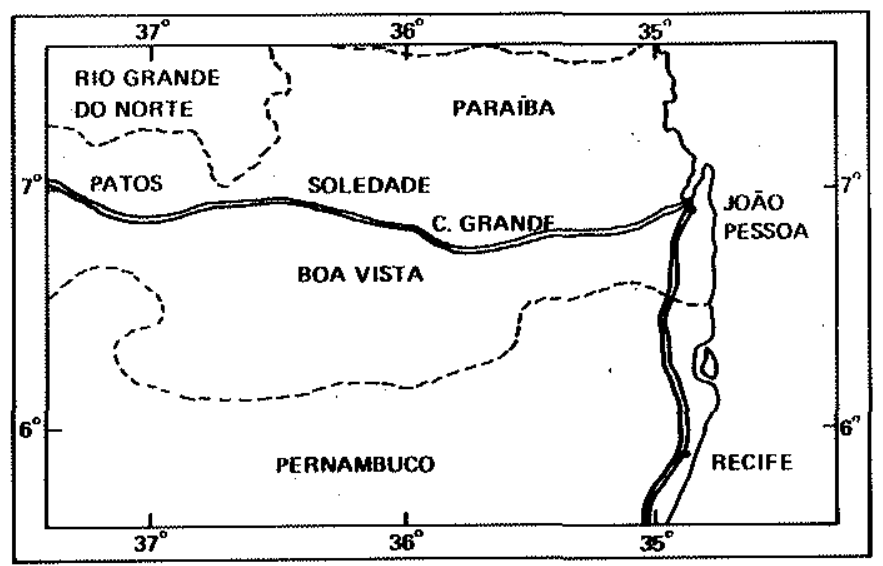

Figura I - Mapa de localização da região de Boa Vista, Paraíba

Ainda não se chegou a um consenso sobre a gênese da bentonita dessa região por falta de estudos sistemáticos e detalhados, de campo e de laboratório. Caldasso (1965, 1979) atribuiu a gênese da argila à decomposição do mineral plagioclásio e dos minerais ferromagnesianos, em ambiente lacustre, de água alcalina, baseando sua teoria no teor acentuado de ferro e magnésio observado nas argilas. As evidências obtidas no campo levaram Pinto e Pi- mentel (1968) à conclusão de que as argilas foram originadas a partir da alteração de basalto. Após uma avaliação profunda da geologia e da gênese das argilas bentoníticas distribuídas no mundo inteiro, Grim e Guven (1978) classificaram as ocorrências de bentonita nas quatro classes seguintes, segundo a gênese: 1) alteração de cinza e tufo vulcânicos essencialmente in situ ; 2) alteração hidrotermal de rochas ígneas, geralmente; 3) alteração deutérica de rocha ígnea; e 4) origens diversas, de caráter duvidoso e que não podem ser estabelecidas com precisão. Esta classificação de Grim e Guven tem como base as características geológicas, estratigráficas e modo de ocorrência dos vários depósitos de bentonita.

Neste trabalho, apresentam-se características geológicas das jazidas bentoniticas de Boa Vista, suas litologias associadas, suas relaçð̃es estratigráficas, bem como uma interpretação genética das mesmas, por meio de um modelo construído com base nos dados citados, objetivando ampliar os conhecimentos sobre a gênese da bentonita de Boa Vista.

MODO DE OCORRÉNCIA DA BENTONITA As argilas bentoníticas de Boa Vista ocorrem e são lavradas em pequenas bacias cuja forma tende a ser circular: oito dessas bacias atualmente conhecidas alinham-se na direção leste-oeste, segundo uma distância de $10 \mathrm{~km}$. A cor da argila varia entre e dentro de cada bacia bem como há bacias contendo argila de uma só cor. As argilas e os sedimentos associados (areia e calcedônia) mostram estratificação horizontal ou ondulada. Foram encontrados nas jazidas fósseis de madeira silificada, ficando assim estabelecido o ambiente continental para os sedimentos argilosos. As bacias de argila são cercadas por granitos a oes- 


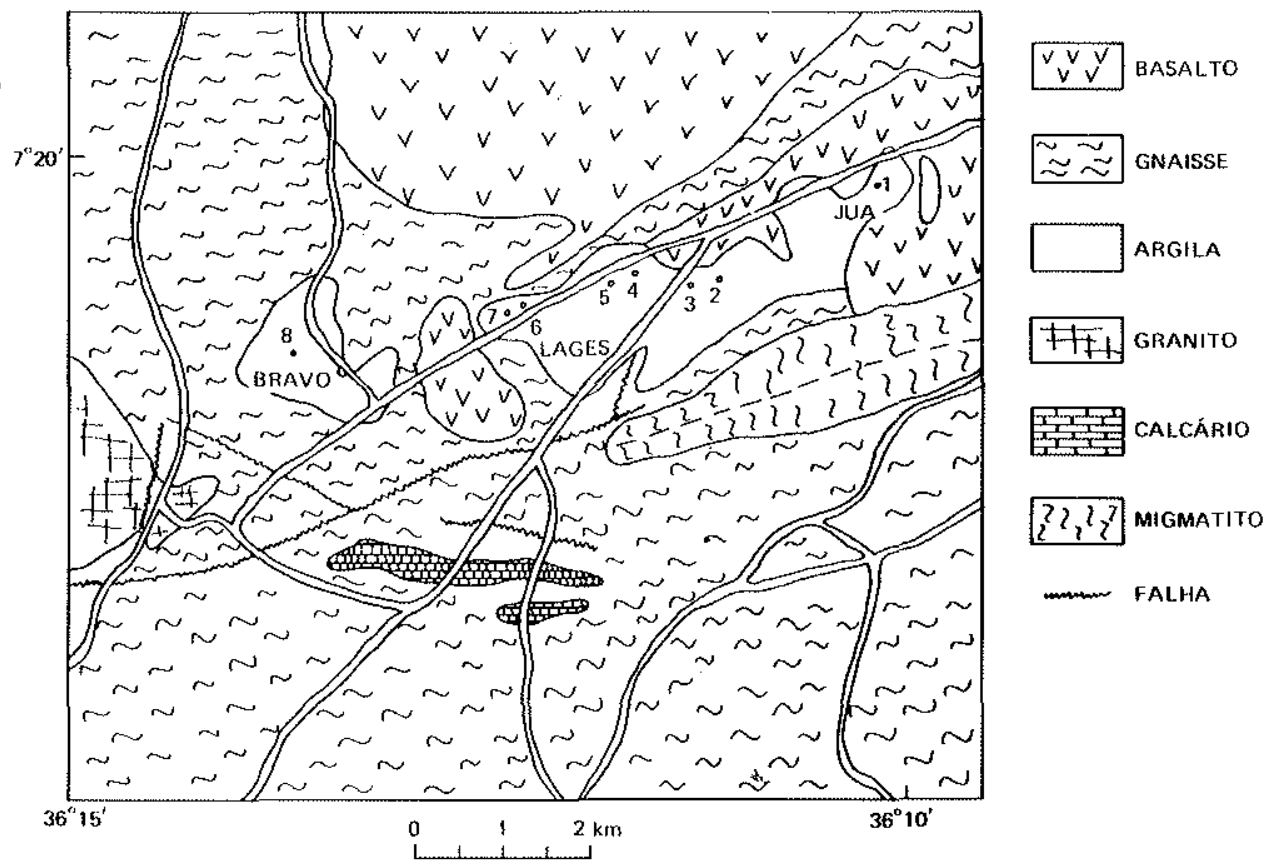

Figura 2 - Mapa geológico da área de ocorrência de argila, mostrando as posiçoes das minas estudadas (Mapa do DNPM, 1968, modificado)

te; gnaisse e migmatitos ao sul, ao norte e a noroeste; e basaltos a leste e a nordeste (Fig. 2), constituindo elevações que circundam a faixa de ocorrência das argilas, que ocorrem, portanto, numa depressão topográfica da região.

Segue-se uma discussão das características geológicas, litológicas e estratigráficas das argilas bentoníticas nas áreas Juá, Lages e Bravo.

Área Juá As argilas da área Juá ocorrem numa bacia alargada na direção E-W com uma extensão de $200 \mathrm{~m}$. A espessura do material é bastante variável, sendo maior em suas extremidades $(5 \mathrm{~m})$ e menor $(1 \mathrm{~m})$ na parte c̈entral. Esta variação é resultante de ondulações da superfície do embasamento dos sedimentos argilosos.

A sequiência litoestratigráfica neste local é a seguinte: o embasamento é formado por rocha basáltica de cor cinza-esverdeada e decomposta, exceção da parte central da bacia, onde a espessura do minério é mínima e a rocha basáltica apresenta-se fresca, com cor escura. Nesta bacia, o derrame basáltico do embasamento dá a impressão de continuidade com o basalto aflorante em suas bordas. Sobre o embasamento de natureza vulcânica segue wse a argila bentonítica com o contato litológico entre eles, tendendo a ser brusco. No local onde a argila é mais espessa encontra-se uma camada de $1 \mathrm{~m}$ de arenito fino. Também os contatos litológicos entre o arenito e a argila são bruscos. Ainda se observam mini-intercalações de areia por toda a sequiência argilosa.

Na parte superior da seqüência aparecem, caracteristicamente, minibacias de interlaminações finas e rítmicas de argila e calcedônia. Estas minibacias, em perfil, têm comprimento de 10 a $15 \mathrm{~m}$ e profundidade de 1 a $2 \mathrm{~m}$, cobrindo toda a seqüência. As minibacias apresentam forma côncava para cima com as laminaçôes sendo, desta forma, igualmente côncavas (Fig. 3). A variação vertical das litologias na área Juá é demonstrada na Fig. 4.

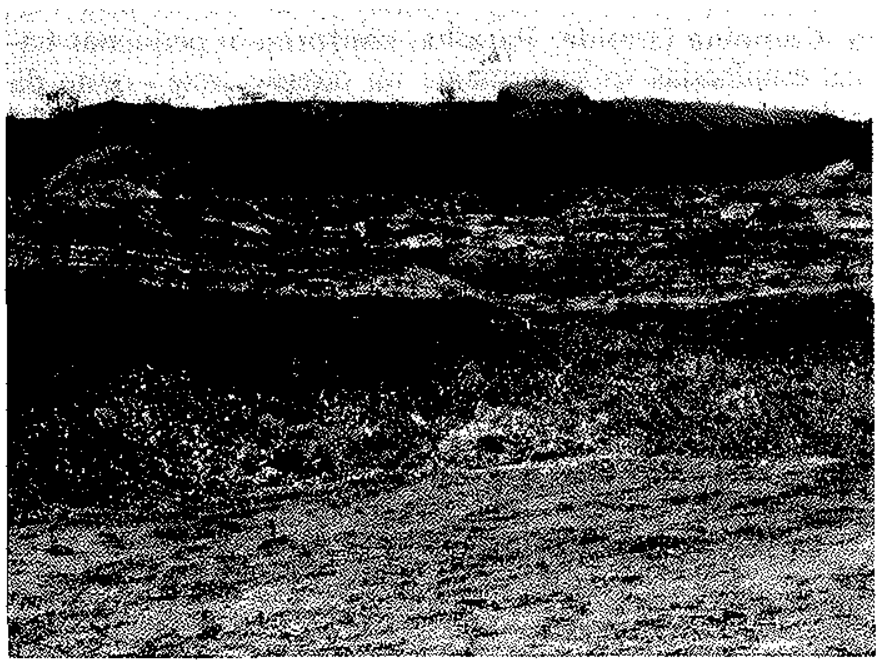

Figura 3 - Minibacia com interlaminações de argila e cal cedônia, Juá

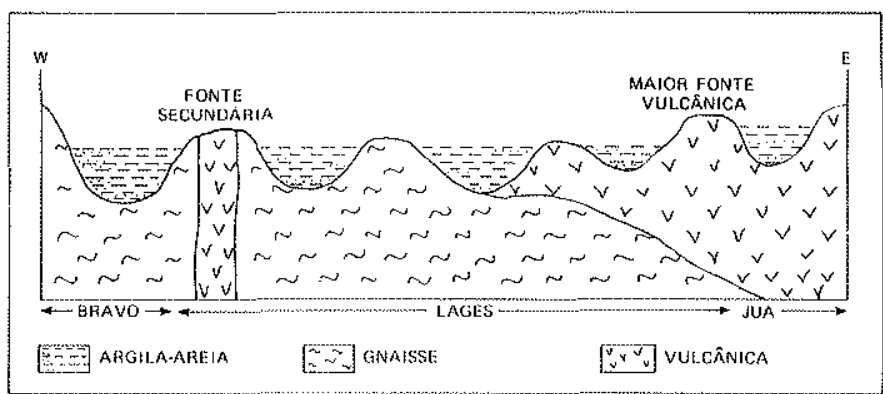

Figura 4 - Seqüência verticais das litologias observadas nas áreas Juá, Lages e Bravo 
A bacia de Juá é flanqueada nos lados leste e oeste por derrame de basalto de cor escura e textura afanítica. Este derrame aflora formando um relevo bem acentuado dentro de uma extensão de $0,5 \mathrm{~km}^{2}$. O derrame apresenta-se com as seguintes estruturas vulcânicas: juntas colunares, zona de vitrificação na parte superficial e estrutura fluidal de lava (Fig. 5).

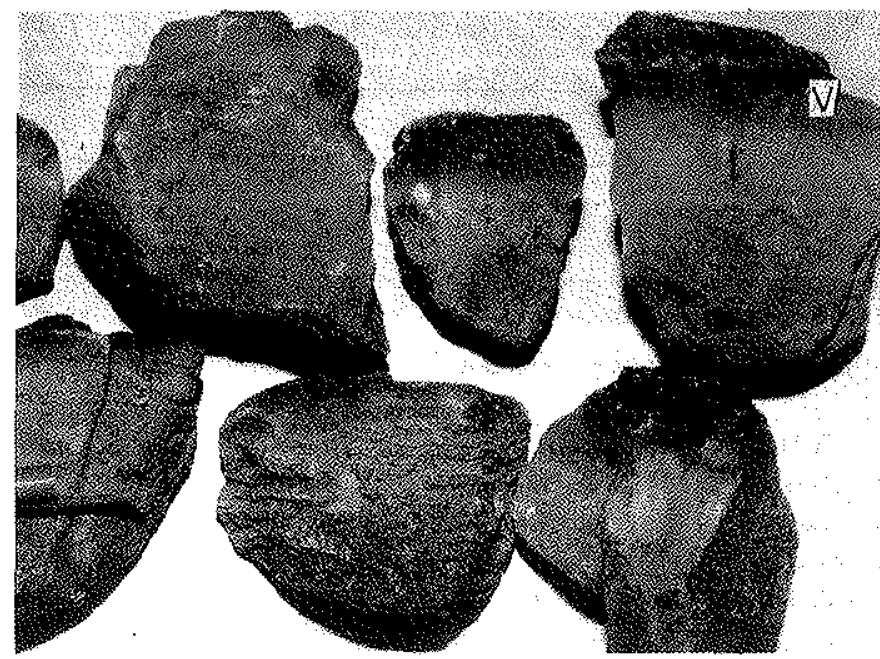

Figura 5 - Amostras de derrame com as estruturas colunar, fluidal e zonas de vitrificação (v), Juá

Foram encontrados sobre o derrame blocos de lava aglomerática contendo fragmentos angulares de vidro vulcânico com diâmetro máximo de $3 \mathrm{~cm}$ (lapilli) (Fig. 6).

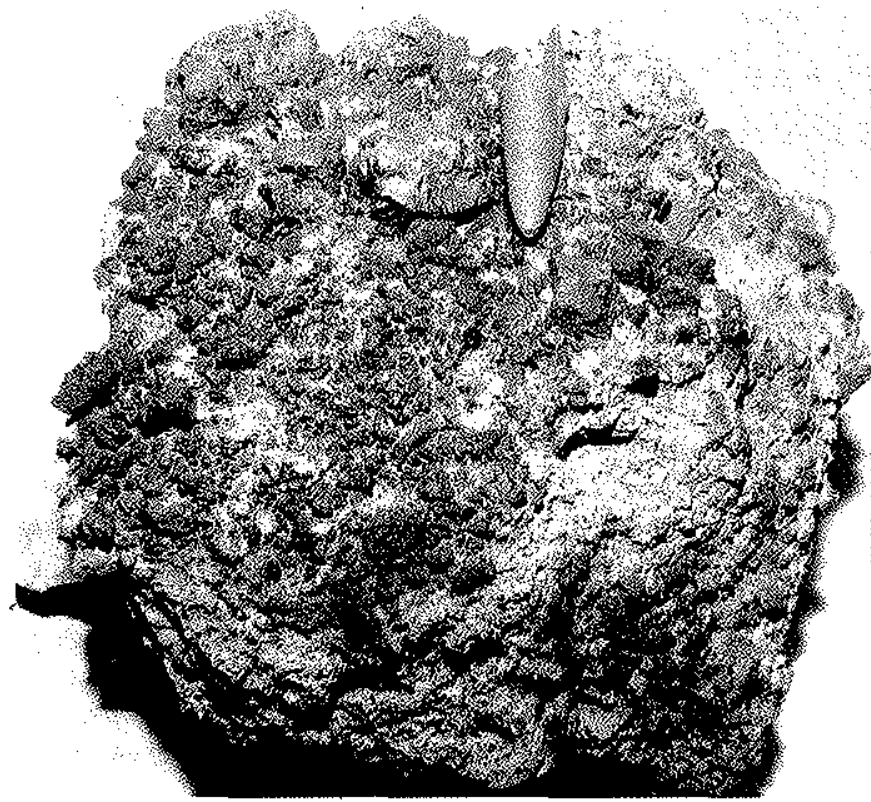

Figura 6 - Tufo lapilli contendo fragmentos de vidro vulcâni. co e basalto vitreo, Juá

Assim, as evidências apontam uma fonte vulcânica, aparentemente de maior importância, fornecedora de materiais piroclásticos e lava na região.
Área Lages As jazidas da área Lages são mais heterogêneas, tanto do ponto de vista litológico quanto do ponto de vista cromático, ocorrendo litologias nãobentoníticas associadas ao material. Atualmente existem seis jazidas em lavra (Fig. 2).

As bacias onde se encontram as jazidas $(2,3,4$ e 5), situadas na parte leste, caracterizam-se pela presença de rochas basálticas em seu embasamento, bem como são cercadas por derrames de lavas básicas. As rochas basálticas do embasamento, de cor cinza-esverdeada e decompostas, são altamente vesiculares tornando-se escoriáceas. A superfície topográfica do embasamento apresenta-se bastante ondulada, alcançando desnível de $1 \mathrm{~m}$. Nestes casos, as laminações de argila e dos sedimentos intercalados apresentam-se conformáveis, acompanhando perfeitamente as ondulações do embasamento.

Em alguns locais (bacias 2 e 3), a rocha basáltica do embasamento revela continuidade para o derrame aflorante nas bordas da bacia (Fig. 7).

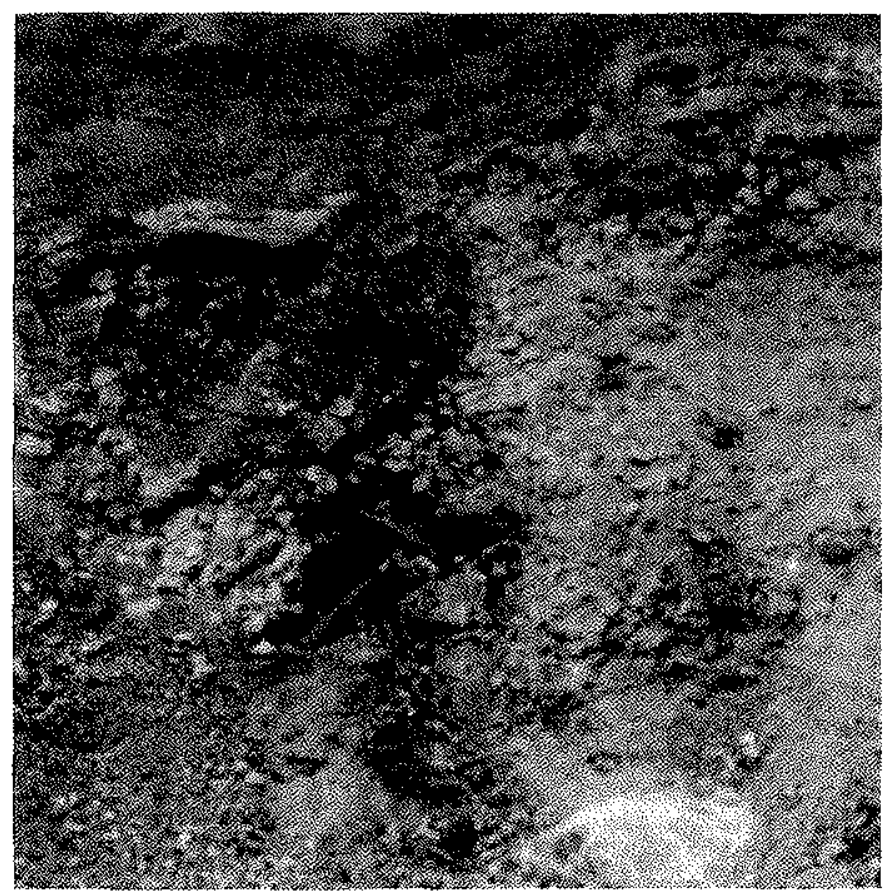

Figura 7 - Borda da bacia de argila, mostrando continuidade de basalto escoriáceo, do embasamento à superfície. A parte superior é constituida de solo preto (massapé), Lages

Isso demonstra a associação genética entre a rocha de embasamento e o derrame exposto ao redor das bacias.

A espessura da seqüência argilosa na área Lages varia entre 2 e $7 \mathrm{~m}$. A seqüência é, geralmente, iniciada por uma camada de arenito, bem selecionada e friável (bacias $2,3,4)$. Uma exceção é a bacia 3 , onde foi observada uma camada de conglomerado contendo seixos subangulares de rocha basáltica decomposta (Fig. $8 a$ ).

Os seixos têm diâmetro máximo de $20 \mathrm{~cm}$, sendo litologicamente semelhantes às rochas basálticas do embasamento. A matriz deste conglomerado é constituída de areia quartzosa, média a fina, bem selecionada, na qual se observam traços de tubos escavados por fósseis (Fig. $8 b)$. 


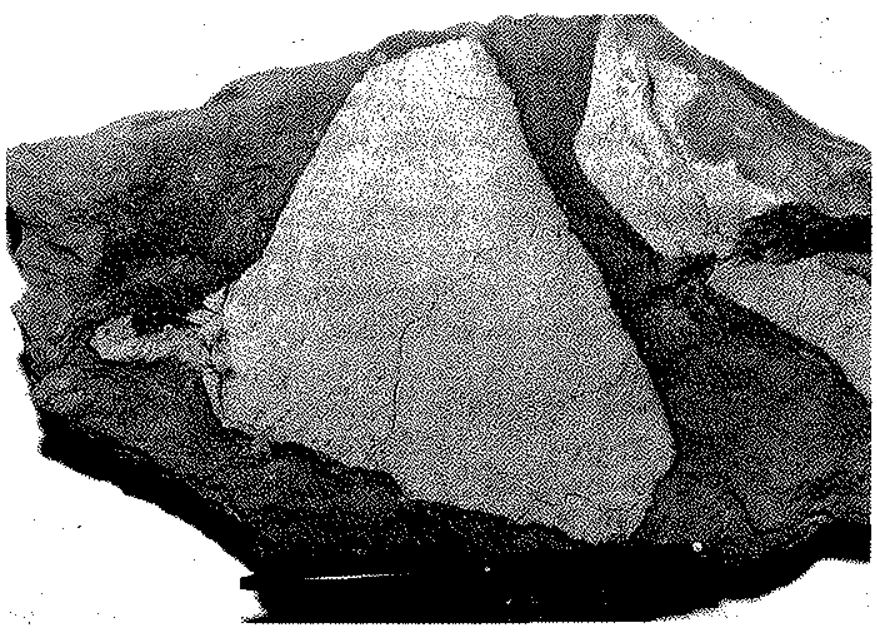

(a)

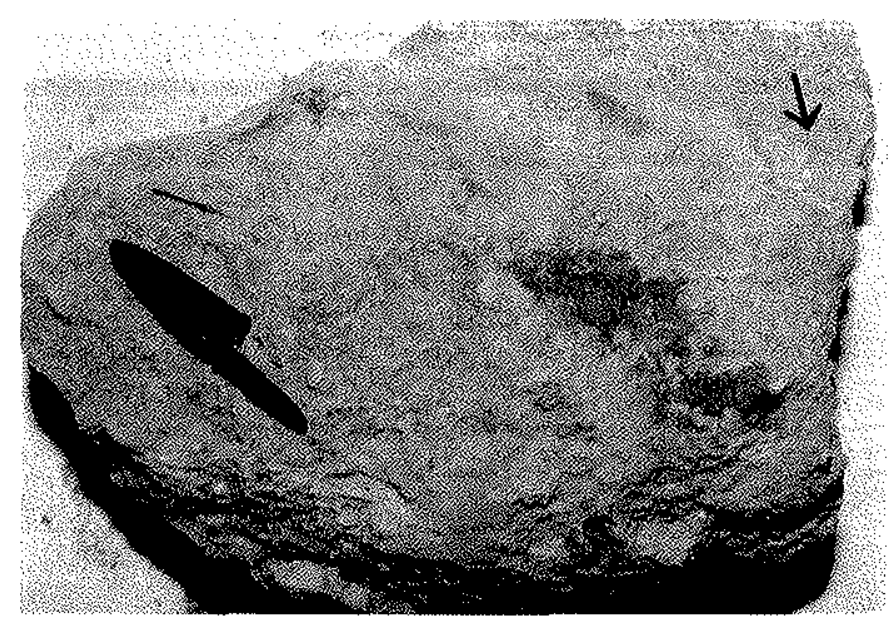

(b)

Figura 8 - (a) Conglomerado com seixos subangulares de ba salto decomposto, embutido em matriz arenosa, Lages, e (b) a matriz arenosa do conglomerado do basalto, mostrando traço de um tubo de fossil, Lages

Assim, as evidências demonstram a existência de bacias nas quais se acumularam os sedimentos detriticos com os seixos de basalto, derivados de altos topográficos situados ao redor da bacia maior. Esses sedimentos foram retrabalhados por invertebrados que deixaram os traços registrados na matriz arenosa do conglomerado.

No meio da seqüência aparece a argila bentonítica mostrando laminações horizontais com intercalações ocasionais de pequenas lentes de areia. A parte superior é caracterizada pelas minibacias de interlaminações rítmicas de argila e calcedônia, com as mesmas características dimensionais da bacia de Juá.

Podem ser observadas várias dessas minibacias cobrindo a seqüencia de argila, em qualquer depósito da área em questão. Em alguns locais, a seqüência termina com lentes de conglomerado com seixos de quartzo. A Fig. 4 mostra a disposição das várias litologias nesses locais.

As bacias situadas na parte oeste de Lages (bacias $6 \mathrm{e}$ 7) diferem das outras descritas acima em que a seqüencia é iniciada pela presença de gnaisse no embasamento em vez de rocha basáltica (Fig. 9).

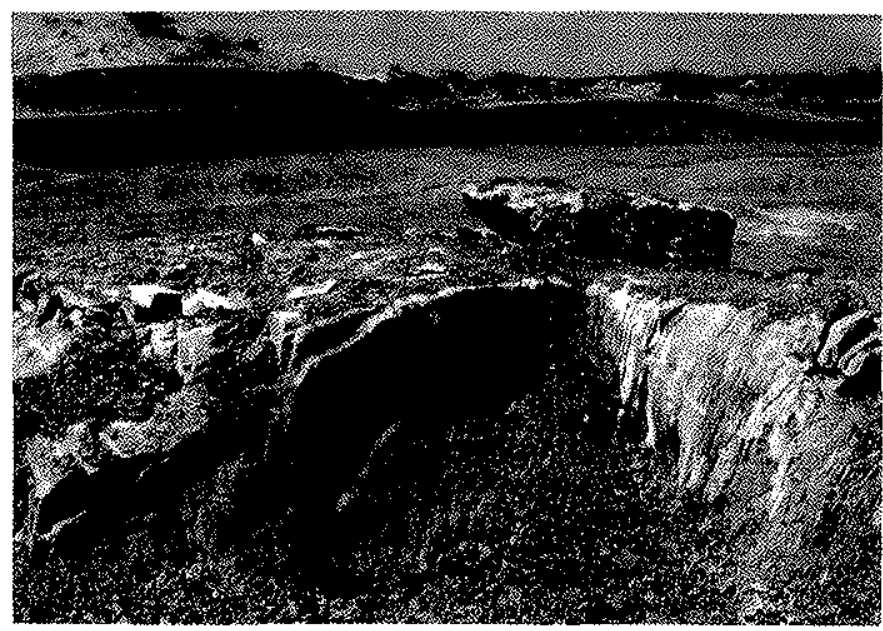

Figura 9- Gnaisse no embasamento da bacia de argila, Lages

A superfície topográfica do embasamento é altamente irregular e ondulada, resultando em uma grande variação na espessura da argila. Uma camada de arenito, médio a grosso, é conglomerática e ocorre sobre o embasamento, seguindo-se para o topo argila bentonítica, a qual tem contato brusco com o arenito (Fig. 10).

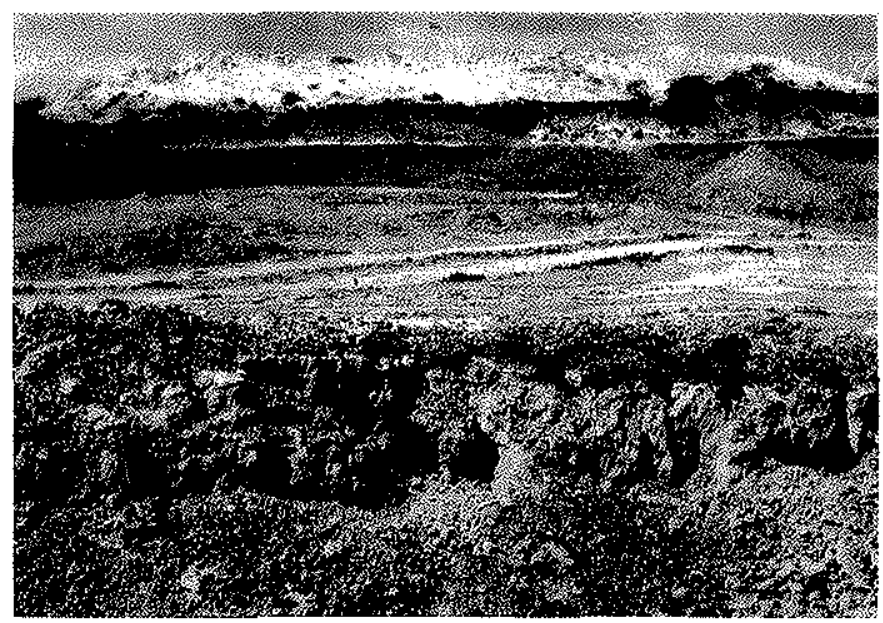

Figura 10 - Camada de arenito acima de gnaisse tendo contatos bruscos, Lages

A cor da argila é predominantemente verde, contrariando a encontrada em outras jazidas, onde ocorrem com várias tonalidades. As minibacias de argila e calcedônia não aparecem nesta e nas demais bacias para oeste. Esta bacia é cercada por gnaisse em seus limites norte, leste e oeste, e pelo basalto, em seu limite sul. Aproximadamente $400 \mathrm{~m}$ a oeste da bacia 3 encontra-se um afloramento de um dique de diabásio. Para oeste do lado do dique, existem duas jazidas abandonadas, nas quais se observa novamente gnaisse como embasamento das argilas. A seqüência litológica encontrada nessas bacias está apresentada na Fig. 4.

Área Bravo A bacia Bravo é a de maior dimensão e de maior profundidade entre as demais existentes na área de Boa Vista. Sua profundidade, observada através de um furo de sondagem, é de cerca de $35 \mathrm{~m}$, quando se alcança o embasamento de gnaisse (Pinto e Pimentel, 1968). Na 
borda da bacia, a oeste, observa-se uma maior intercalação de conglomerado, arenito e siltito com as argilas bentoníticas (Figs. 11 e 4 ).

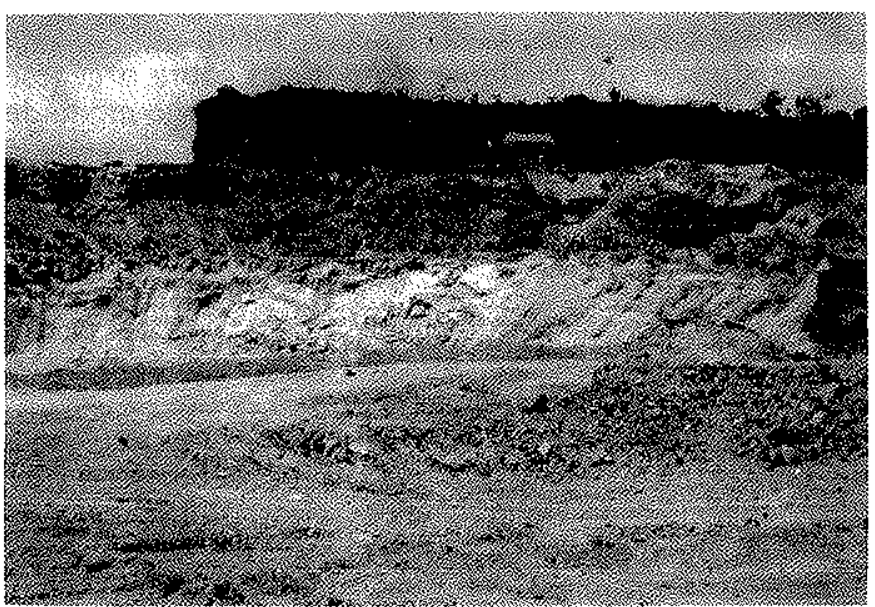

Figura 11 - Seqüência das intercalações de arenito, siltito e argila da bacia Bravo

Essas intercalações ocorrem em forma de lençois nos vários níveis de seqüência, resultando numa espessura total de $10 \mathrm{~m}$. Um estudo sobre a variação vertical e lateral das estruturas, texturas, litologia e geometria desses depósitos mostrou que os detritos foram depositados em ambiente de leque aluvial (Gopinath et al., 1979). Circundando a bacia ocorrem granitos, gnaisses e migmatitos, mas não há presença de rochas básicas neste local. Não foram observadas as minibacias de interlaminações de argila e calcedônia associada com a argila.

\section{ASPECTOS PETROGRÁFICOS DO DERRAME BASÁLTICO ASSOCIADO COM A BENTONITA Ob-} jetivando conhecer a natureza litológica dos derrames basálticos que ocorrem no embasamento das bacias de bentonita e os que afloram nas regiões entre as bacias, foram realizadas análises petrográficas em 25 amostras. Megascopicamente, os derrames subjacentes às argilas exibem as cores cinza e cinza-esverdeada, e apresentam-se sempre de estrutura vesicular, passando à estrutura de pedra-pomes ou de escória (Fig. 12).

Foram feitas análises modais pela contagem de 300 pontos sobre cada amostra e a freqüência relativa de cada
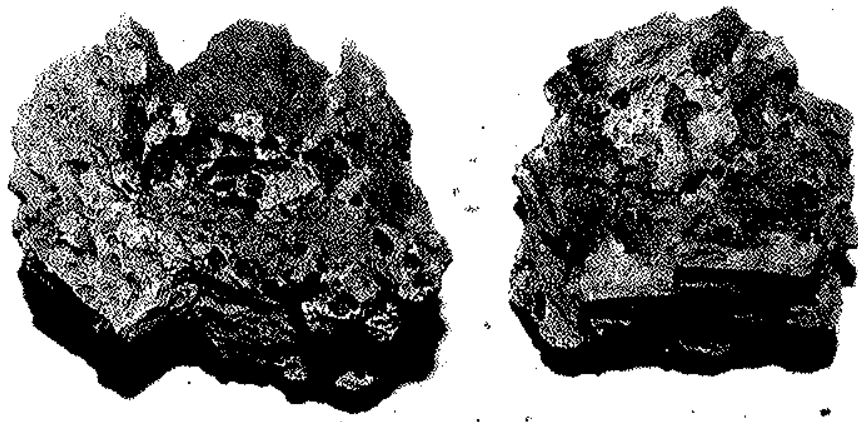

Figura 12 - Rocha basáltica de cor cinza, vesicular e escoriácea, do embasamento das argilas, Lages componente da rocha, para vários tipos litológicos, é mostrada na Tabela 1.

Tabela l - Composição mineralógica das rochas básicas asso. ciadas a argilas bentoníticas

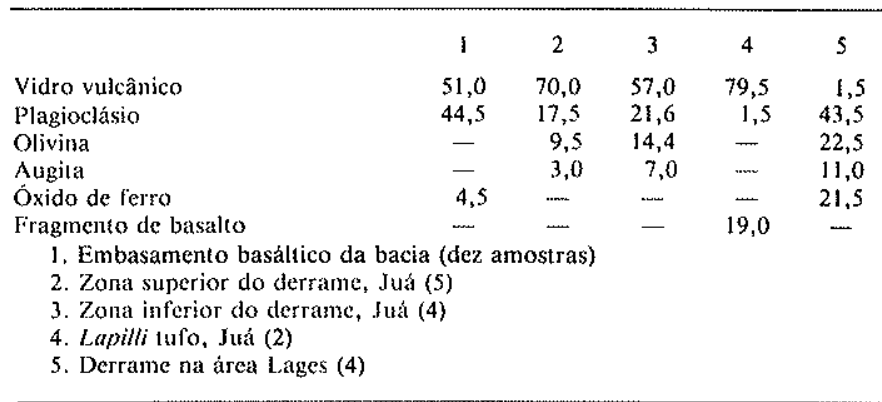

O derrame basáltico do embasamento das argilas é constituído de vidro vulcânico e plagioclásio. $O$ vidro vulcânico mostra devitrificação para quartzo microcristalino e argilo-minerais (Fig. 13).

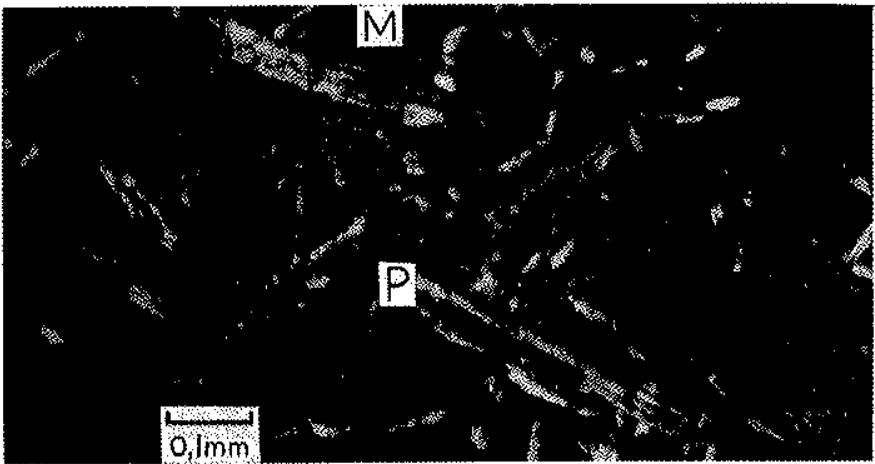
(a)

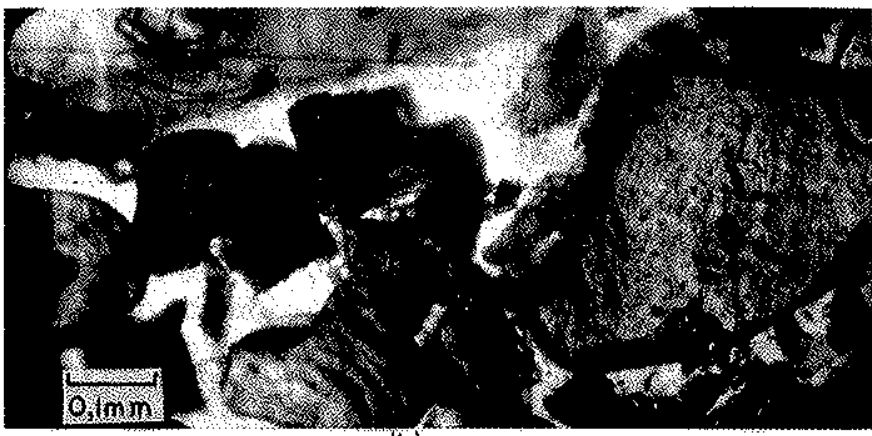

(b)

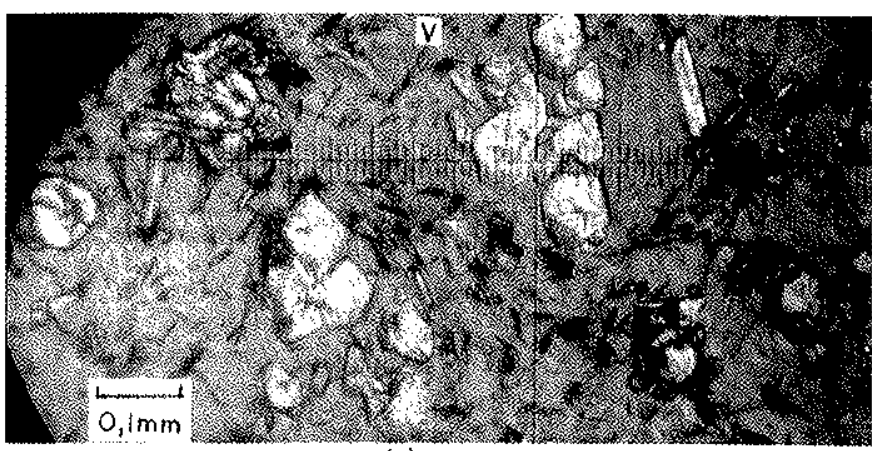

(c)

Figura 13 - (a) Rocha basáltica do embasamento, com plagioclásio $(P)$ substituído por calcedônia, embutido na matriz (M) argilosa devitrificada de vidro; (b) tufo a lapilli com fragmentos angulares de vidro vulcânico e basalto vítreo, Juá; (c) basalto vitreo adjacente à bacia de Juá, com microcristais de olivina e plagioclásio na massa vítrea 
Este vidro mantém seu aspecto original (estrutura reliquiar), mostrando cor castanha em luz polarizada, sendo, às vezes, parcialmente devitrificado. Os plagioclásios apresentam-se parcialmente substituídos por calcedônia, sem qualquer alteração para argilo-minerais. Os minerais augita e olivina não foram observados nesta rocha, talvez motivado por alteração completa das mesmas ou pela ausência. Todas as amostras do embasamento manifestam essas características, inclusive os seixos de basalto do conglomerado subjacente às camadas de argila.

Os derrames basálticos que afloram nos flancos da bacia Juá são geralmente vesiculares, apresentando zonas vitrificada, juntas colunares e estruturas fluidais (Fig. 5). Foram encontrados blocos de tufo a lapilli espalhados sobre a superfície do derrame. A análise modal deste material mostrou que ele é constituído de fragmentos de vidro vulcânico e fragmentos de basalto vítrico. $O$ vidro vulcânico é de cor castanho-clara e os fragmentos de basalto vítrico têm textura vitrofírica, com coloração também castanho-clara, contendo micrólitos de olivina, plagioclásio e inclusões fluidas (Fig. 13b).

A rocha basáltica do derrame, em ambos os lados de Juá, é altamente vesicular, variando entre pedra-pomes ou escória. Esta rocha mostra textura vitrofírica com cristais esparsos de plagioclásio e olivina, com inclusões fluidas em uma massa predominantemente vítrea (Fig. $13 c)$.

Em sua composição, o vidro vulcânico supera outros minerais em abundância (coluna 2, Tab. 1). Abaixo da parte superficial do derrame, a rocha conserva ainda a textura vitrofírica com a orientação fluidal do plagioclásio bem como cristais de olivina euédrica, numa massa de vidro vulcânico (coluna 3, Tab. 1 ).

Os blocos de tufo a lapilli, que ocorrem acima do derrame, são constituídos de materiais litologicamente semelhantes às do derrame. Isso demonstra que uma erupção gasosa e explosiva resultou na formação de material piroclástico em quantidade muito maior que a encontrada atualmente.

Por outro lado, os derrames que afloram entre as bacias e o norte da área Lages são constituídos de basalto escuro e afanítico, apresentando, ocasionalmente, o aspecto vesicular. Ao contrário dos derrames da área Juá, estes são caracterizados por plagioclásio $(43,5 \%)$, olivina $(22,5 \%)$, augita $(11,0 \%)$, oxido de ferro $(21,5 \%)$ e vidro vulcânico $(1,5 \%)$. Assim, o vidro vulcânico tende a ser menos importante nessas rochas.

Litologicamente, podem-se distinguir dois derrames distintos: o primeiro, resultante de uma erupção gasoșa e explosiva, teve caracteres de lava vitrea e materiais piroclásticos (tufo a lapilli); e o segundo, uma erupção quiescente formou uma lava de natureza não-vítrea.

DISCUSSÃo A gênese clássica da bentonita envolve a devitrificação e alteração de materiais piroclásticos, tais como cinza e tufo em ambiente marinho. Esses jazimentos possuem grande extensão lateral e pequena extensão vertical (Grim e Guven, 1979). As jazidas de Boa Vista, sem dúvida, são de origem continental, evidenciada pela ocorrência de troncos de madeira fossilizados e pela ausência de fósseis de origem marinha.

São conhecidas ocorrências de argilas bentoníticas de origem continental em várias partes dos continentes. Em sua maioria, resultaram de alteração da cinza e tufo em ambiente lacustre, por vezes intercalados com sedimentos detríticos (Bordas, 1943; Termier et al., 1956; Konta, 1957; Carlson e Rogers, 1974; Loughnan e See, 1959; Obradovic e Knezevic, 1972; Ritchie, 1969).

Acredita-se que qualquer proposição sobre a gênese das argilas de Boa Vista deve também explicar o modo de origem de todas as características geológicas inerentes a esses depósitos. Assim sendo, apresenta-se a seguir uma interpretação sobre as feições geológicas das argilas bentoníticas da região.

Natureza litológica do embasamento dos depósitos As argilas bentoníticas ocorrem sobre as rochas basálticas de tipo escória ou pedra-pomes na parte leste da região (Juá e Lages) e sobre gnaisse e migmatito a oeste da região (Lages e Bravo). Os basaltos afloram entre as bacias de argila nas áreas de Juá e parte leste de Lages enquanto na parte oeste desta região não ocorre basalto, mas afloram gnaisses e um dique de diabásio (Fig. 2). A linha de contato entre argila e embasamento é muito irregular e ondulada, onde as laminações das camadas de argila acompanham, paralelamente, as irregularidades de embasamenio.

Aparentemente, esta região de ocorrência de argila parece ter sido uma faixa topográfica baixa cercada pelas rochas cristalinas da região. Nesta faixa, acredita-se, existiam pequenas depressões ou bacias, as quais foram preenchidas por argilas $\mathrm{e}$ outros sedimentos. As evidências encontradas no derrame localizado nos flan$\cos$ de bacia Juá indicam enfaticamente uma fonte de derrame e de material piroclástico. A erupção, neste local, foi iniciada pelo tipo explosivo por causa da presença abundante de gás, resultando na fragmentação da lava que formou o material piroclástico (Hyndman, 1972). Os derrames de lava escória e vesicular ocuparam o embasamento das bacias de Juá e do leste de Lages, seguidos por acumulação de material piroclástico. Esse material piroclástico, constituído de vidro vulcânico, foi transportado para as bacias, seja pelo vento, seja pela água, onde se transformou, posteriormente, em argilas montmoriloníticas num ambiente lacustre alcalino. $O$ primeiro derrame escoriáceo não chegou até o extremo oeste da região, resultando, apenas, em acumulação de material piroclástico sobre os gnaisses e migmatitos do embasamento.

É conhecido que a cinza e o tufo se devitrificam para argila esmectita, simultaneamente a sua acumulação em ambiente alcalino (Grim, 1958; Blatt et al., 1972; Grim e Guven, 1979). As bentonitas formadas por este processo tendem a ser puramente esmectíticas. As argilas bentoníticas de Boa Vista são constituídas de uma mistura de nontronita ou nontronita-beidelita, com ilita, caulinita e camadas mistas de ilita-montmorilonita (Caillaux e Cunha, 1969; Santos 1970; Schuster et al., 1981). O teor ponderal do argilo-mineral montmorilonita nas argilas de Boa Vista varia entre $55 \%$ e $70 \%$. Isso, pelo fato de nos ambientes continentais existirem alta propabilidade de contaminação por argilo-minerais detríticos oriundos de intemperismo de rochas circunjacentes, neste caso as rochas graníticas e gnaisses circunjacentes. Ainda, a lixiviação da argila já formada pode modificar a composição mineralogica da bentonita, o que não aconteceria em ambiente marinho (Loughnan, 1969). 
As intercalações dos sedimentos dentríticos grosseiros Geralmente, todas as seqüências contêm uma camada de arenito ou siltito na base, bem como pequenas intercalações deste material na parte média das mesmas. Mineralogicamente, essas camadas de sedimentos grosseiros contêm, predominantemente, quartzo, além de feldspato indicando as rochas graníticas como fonte desses materiais detríticos. Como foi visto, em uma das bacias ocorre uma camada de conglomerado, na base da seqüência, contendo seixos de basalto alterado. Acreditase que esses seixos que jaziam nas bordas da bacia foram carregados juntamente com os sedimentos grosseiros, posteriormente alterados durante a formação da argila pela água intersticial da areia. Esta areia, de granulação média e fina, tende a ser bem selecionada, ferruginosa e apresenta traços de tubos de fósseis. Não foi observada a presença de material basáltico na fração de areia, indicando que os basaltos não foram decompostos anteriormente a sua acumulação como os sedimentos grosseiros.

'A ausência de estruturas sedimentares primárias, além de outras características observadas leva a concluir que os detritos se acumularam por ocasião de ocorrência eventual de torrentes nas bacias, normalmente em condições de sedimentação do tipo lacustre. As numerosas intercalações de areia na sequiência de argila evidenciam vários episódios de deposição torrencial. Pode-se conjecturar que as torrentes eram resultantes de fortes chuvas prevalecentes na época. Caso a argila seja resultado da alteração da rocha básica in situ, torna-se difícil explicar intercalações ocasionais de sedimentos detríticos na mesma. É possível explicar essas intercalações considerando que o material que deu origem à bentonita seja também de natureza clástica ou piroclástica.

Interlaminações ritmicas de argila e calcedônia As minibacias com interlaminações rítmicas de argila e calcedônia sempre ocorrem na parte superior, cobrindo as argilas bentoníticas. Por coincidência ou não, o embasamento das bacias onde existem essas minibacias é constituído de rocha basáltica vítrea e escória. As bacias na parte oeste de Lages e Bravo são constituídas de gnaisse em seus embasamentos, não apresentando as minibacias de interlaminaçőes de argila e calcedônia. A alteração de cinza ou tufo para argila moutmorilonítica precisa de um pH moderadamente alcalino e a precipitação de sílica só se verifica num ambiente ácido, em função de coeficiente de concentração de silício em solução (Grim e Guven,
1979; Blatt et al., 1972; Eugster e Chou, 1973; Loughnan, 1969). O processo de devitrificação do material piroclástico é acompanhado pela produção de sílica em solução. A precipitação de sílica ocorre quando sua concentração atinge certo nível pela devitrificação e/ou pela evaporação, produzindu sílica gel com a conseqüente mudança do $\mathrm{pH}$ de ambiente. Em tempo de chuva, o influxo de águas nas bacias diminui a concentração do silício com conseqüente variação no $\mathrm{pH}$, assim interrompendo o processo de precipitação da sílica. $\mathrm{Na}$ ocasião de agitação da água da bacia, causada pelo influxo de água, a argila ou outros detritos finos são levados em suspensão e depositados sobre a lâmina de calcedônia precipitada anteriormente. Repetição dessas mudanças no ambiente das bacias possibilitam as interlaminaçðes rítmicas da argila calcedônia observadas nas bacias de Boa Vista. Assim, interpreta-se que a variação sazonal (seca e úmida) resultou na formação de interlaminações rítmicas de argila e calcedônia nos poços de água que existiam nas bacias que deram origem às argilas bentoníticas da região.

CONCLUSÕES As evidências apresentadas neste trabalho demonstram que as argilas bentoníticas da região de Boa Vista são resultantes de alteração dos materiais piroclásticos de natureza tufo a lapilli, oriundo de vulcanismo local. Prováveis fontes desses materiais podem ser observadas na parte leste da região. $\mathrm{Na}$ região podem-se reconhecer dois tipos litológicos distintos de derrames associados às argilas. $O$ primeiro tipo, subjacente às argilas, tendo aspecto de escória e/ou pomes, contém vidro vulcânico em abundância. Esses derrames também são expostos nas áreas entre as bacias para leste. A natureza litológica desse derrame indica uma atividade explosiva resultando na formação dos materiais fragmentários. Esses materiais fragmentados acumularam-se nas paleodepressões sobre o derrame escoriáceo ao leste e sobre rochas gnáissicas a oeste, porque o derrame escoriáceo não chegou a ocupar as bacias a oeste. O segundo tipo de derrame, sendo não-vesicular e não vítreo, oriundo de vulcanismo latente, ocorre adjacente ao norte das jazidas.

Os materiais fragmentários, formados durante a atividade explosiva, são constituídos, em sua maioria, de vidro vulcânico e foram depositados nas paleodepressões de ambiente lacustre. Contudo, as paleodepressões foram locais de acumulação dos detritos grosseiros com atividade orgânica antes de seu preenchimento por material pi-

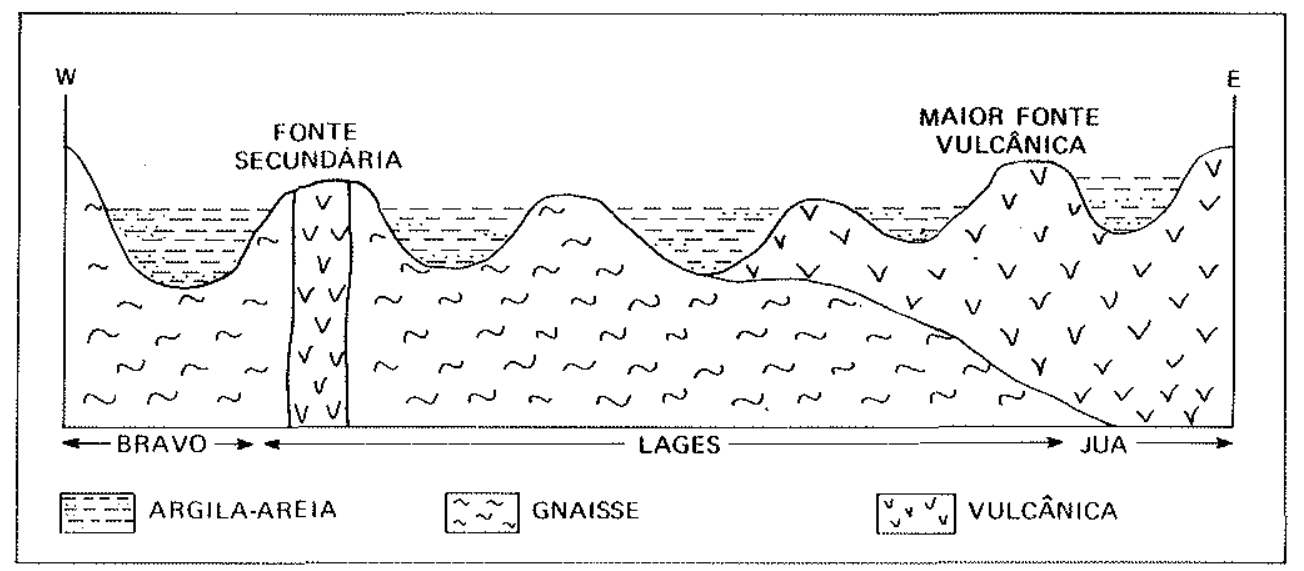

Figura 14 - Perfil de modelo geológico das bacias de argila e suas relaçóes litoestratigráficas na região de Boa Vista 
roclástico. A devitrificação dos materiais vítreos, em condições alcalinas, resultou na formação de argilas montmoriloníticas. Aparentemente, a sillica produzida durante a devitrificação do vidro vulcânico (que produziu também a argila das bacias) migrou para a parte superior do depósito. Aí, foi precipitada nas condições ácidas, em formas de lâminas, nos poços de água existentes sobre os depósitos argilosos, desde que as camadas de arenito nas bases das seqüências não tenham sido silicificadas. Comumente, segundo Grim e Guven (1979), as rochas subjacentes à argila bentonítica, na maioria das ocorrências, mostram alto grau de silicificação, o que não acontece com os arenitos subjacentes às argilas bentoníticas de Boa Vista.

A Fig. 14 apresenta um modelo geológico para as jazidas, mostrando a relação estratigráfica e genética entre o derrame, o embasamento cristalino e as bacias de argila bentonítica.

Os resultados obtidos neste trabalho e a natureza de ocorrência das argilas evidenciaram uma variação consi- derável na espessura de camadas de minério na região devido à irregularidade da superfície deposicional. Além disso, a intercalação dos materiais não-argilosos, tais como calcedônia e areia, tendem a exagerar a dimensão de minério. Cremos que esses fatores podem influenciar sobremaneira o cálculo da reserva de argila bentonítica na região de Boa Vista.

Agradecimentos Os autores agradecem ao Conselho Nacional de Desenvolvimento Científico e Tecnológico (CNPq) pela bolsa de pesquisador aos Professores Gopinath e Schuckmann, e pelo auxílio de pesquisa do CNPq (Proc. 0600/18440/30) concedido ao Professor Gopinath para execução deste trabalho.

Agradecimentos são devidos ao Prof. José do $\mathrm{Pa}-$ trocínio Tomaz Albuquerque e ao Revisor da Revista Brasileira de Geociências pelas valiosas revisões e críticas final do texto.

\section{BIBLIOGRAFIA}

BLATT, H.V. - 1972 - Origin of Sedimentary Rocks. Prentice-Hall, Inc., New Jersey, p. 634.

BORDAS, A.F. - 1943 - Contribución al conocimiento de las bentonitas argentinas. Rev. Minera, Geol. Mineral 14: 1-60.

CAILLAUX, Z.S. e CUNHA, J. - 1969 - Alguns dados sobre argila coloidal tixotrópica de Campina Grande. Anais XXIII Cong. Bras. Geol., SBG, Salvador, Bahia, outubro, pp. 199-219.

CALDASSO, A.L. - I965 - Geologia da jazida da argila de Boa Vista. Sudene (DRN), Série especial n: 2, 18 pp.

CALDASSO, A.L. - 1979 - Novas consideraçðes sobre a gênese e a idade dos depósitos de argilas montmoriloníticas da Paraiba. Atas do IX Simpósio de Geologia do Nordeste, n: 7, 619-626.

CARLSON, J, R. e RODGERS, K.A. - 1974 - The coalgate bentonite. Clays and Clay Miner. 10: 153-172.

EUGSTER, H. P. e CHOU, I.M. 1973 - The depositional environments of Precambrian banded iron - Formations. Economic Geology 68: 1144-1168.

GOPINATH, $\Upsilon$.R., SCHUSTER, H. D. VASCONCELOS, E. E FEITOSA, R. 1979 - Análise ambiental dos arenitos associados com bentonita da Boa Vista, Paraíba. Atas do IX Simpósio de Geologia do Nordeste, n: 7, pp. 215-218.

GRIM, R.E. - 1963 - Clay Mineralogy. McGraw-Hill, N.Y., 422 pp.

GRIM, R.E. e GUVEN, N. - 1978 - Bentonites - Geology, Mineralogy, properties and uses. Developments in Sedimentology 24, 255 pp.

HYNDMAN, D. W. - 1972 - Petrology of lgneous and Metamorphic Rocks. McGraw-Hill, N.Y., 533 pp.
KONTA, J. - 1957 - Clay Minerals of Czechoslovakia. Nakladateistvi.Akademie Ved, Prague, $200 \mathrm{pp}$.

LOUGHNAN, F.C. $-1969-$ Chemical Weathering of the Silicate Minerals. Elsevier, N.Y., p. 154.

LOUGHNAN, F.C. e SEE, G.T. $-1959-$ Bentonite and fuller's deposits New South Wales. Australasian Inst. Min. Metall., proc. 190, 35-104.

OBRADOVIC, J.C. e KNEZEVIC, V. - 1972 - Genesis of the bentonite from the volcanic Sedimentary Series in the Montenegrin litoral region (Yugosla via), Proc. Int. Clay Conf. Madrid.

PINTO, G.G. e PIMENTEL, E. - 1968 - Consideraçð̃es geo-econômicas sobre os depósitos argilosos de Boa Vista, PB. DNPM/4. Distrito, $20 \mathrm{pp}$.

RITCHIE, J.A. el al. $-1969-$ Bentonites in Canterbury. N. Z. J. Geol Geophys 12(4): 583-603.

SCHUSTER, H.D., GOPINATH, T.R. e SCHUCKMANN, W.K. - 1981 - Mineralogical and geochemical analysis of bentonitic clay and associated basaltic flows (manuscript in preparation).

SOUZA SANTOS, P. - 1970 - Estudo tecnológico de argilas montmoriloníticas do distrito de Boa Vista, Municipio de Campina Grande, Paraíba. Tese para concurso à cátedra $\mathrm{n}^{0} 23, \mathrm{UFPb}, 63 \mathrm{pp}$.

TERMIER, H. et al. - 1956 - On the occurrence of bentonite of Miocene age between Menervilte and Dra-el-Mizane, Algeria. Serv. Carte. Geol. 8: 291-301.

Recebido em 30 de setembro de 1981. 